\title{
BMJ Open Measuring the impact of COVID-19 on the quality of life of the survivors, partners and family members: a cross- sectional international online survey
}

\author{
Rubina Shah (D) , ${ }^{1}$ Faraz M Ali (D) , ${ }^{1}$ Stuart J Nixon, ${ }^{2}$ John R Ingram (D) , \\ Sam M Salek (D) , ${ }^{3,4}$ Andrew Y Finlay (D) ${ }^{1}$
}

To cite: Shah R, Ali FM, Nixon SJ, et al. Measuring the impact of COVID-19 on the quality of life of the survivors, partners and family members: a cross-sectional international online survey. BMJ Open 2021;11:e047680. doi:10.1136/ bmjopen-2020-047680

- Prepublication history for this paper is available online. To view these files, please visit the journal online (http://dx.doi. org/10.1136/bmjopen-2020047680).

Received 04 December 2020 Revised 19 April 2021 Accepted 20 April 2021

Check for updates

(c) Author(s) (or their employer(s)) 2021. Re-use permitted under CC BY-NC. No commercial re-use. See rights and permissions. Published by BMJ.

${ }^{1}$ Division of Infection and Immunity, Cardiff University School of Medicine, Cardiff, UK ${ }^{2}$ Multiple Sclerosis Society, Cardiff, UK

${ }^{3}$ School of Life \& Medical Sciences, University of Hertfordshire, Hatfield, UK

${ }^{4}$ Institute of Medicines Development, Cardiff, UK

Correspondence to

Mrs Rubina Shah;

ShahR45@cardiff.ac.uk

\section{ABSTRACT}

Objective This study aimed to measure the impact of COVID-19 on the quality of life (QoL) of survivors and their partners and family members.

Design and setting A prospective cross-sectional global online survey using social media.

Participants Patients with COVID-19 and partners or family members (age $\geq 18$ years).

Intervention Online survey from June to August 2020. Main outcome measure The EuroQol group five dimensions three level (EQ-5D-3L) to measure the QoL of survivors of COVID-19, and the Family Reported Outcome Measure (FROM-16) to assess the impact on their partner/family member's QoL.

Results The survey was completed by 735 COVID-19 survivors (mean age $=48$ years; females $=563$ ) at a mean of 12.8 weeks after diagnosis and by 571 partners and 164 family members $(n=735$; mean age $=47$ years; females $=246)$ from Europe $(50.6 \%)$, North America $(38.5 \%)$ and rest of the world $(10.9 \%)$. The EQ-5D mean score for COVID-19 survivors was 8.65 (SD=1.9, median=9; range $=6-14) .81 .1 \%(596 / 735)$ reported pain and discomfort, $79.5 \%$ (584/735) problems with usual activities, $68.7 \%$ (505/735) anxiety and depression and $56.2 \%(413 / 735)$ problems with mobility. Hospitalised survivors $(20.1 \%, \mathrm{n}=148)$ and survivors with existing health conditions $(30.9 \%, n=227)$ reported significantly more problems with mobility and usual activities $(p<0.05)$, with hospitalised also experiencing more impact on self-care $(p \leq 0.001)$. Among 735 partners and family members, the mean FROM-16 score (maximum score=highest impact $=32$ ) was 15 (median=15, range $=0-32) .93 .6 \%(688 / 735)$ reported being worried, $81.7 \%(601 / 735)$ frustrated, $78.4 \%$ $(676 / 735)$ sad, $83.3 \%(612 / 735)$ reported impact on their family activities, $68.9 \%(507 / 735)$ on sleep and $68.1 \%(500 / 735)$ on their sex life.

Conclusion COVID-19 survivors reported a major persisting impact on their physical and psychosocial health. The lives of their partners and other family members were also severely affected. There is a need for a holistic support system sensitive to the needs of COVID-19 survivors and their family members who experience a major 'secondary burden'.

\section{Strengths and limitations of this study}

- This study provides evidence of the impact on quality of life (QoL) of 'Iong COVID-19' in survivors of COVID-19.

- This study fills an important knowledge gap in measuring the impact of survivors' COVID-19 on the QoL of partners and other family members.

- Large sample size, heterogenous population and use of validated tools to assess QoL impact.

- The study was open to COVID-19 survivors and their family members internationally, but only those active on social media who could read and understand English completed the survey.

- Causal relationships cannot be established among the study variables as the study was cross-sectional.

\section{INTRODUCTION}

The COVID-19 pandemic is causing profound changes across the world, but there is little information on its physical and psychosocial impact on survivors and their families. Despite the need ${ }^{1}$ for information on the lived experience of infected individuals and their family members, there are only sparse data available.

It is important to ascertain COVID-19's immediate and persisting (long COVID-19) impact on those affected and on their families in order to aid healthcare workers and government agencies to better support them. The understanding of how a person's health condition impacts the quality of life (QoL) of other family members has increased over the last decade. ${ }^{2}$

The aim of this study was to assess the impact of COVID-19 on survivors and their family members based on their lived experience of COVID-19 using validated QoL instruments administered using online social media platforms. 


\section{METHODS}

\section{Settings and participants}

This was a prospective cross-sectional global online survey, using an anonymous online questionnaire. The survey was carried out using https://www.onlinesurveys.ac.uk/ on a Jisc platform. ${ }^{3}$ The survey was distributed through social media platforms including Facebook, Twitter, LinkedIn, WhatsApp and Reddit.

\section{Procedure}

Study participants were provided with information about the study via a link in the survey to a 'Participant Information Sheet', where they were informed that participation was voluntary and their data would remain anonymous. Those who decided to take part gave informed consent at the beginning of the survey. Data collection took place from 30 May to 30 August 2020.

The study was only open to individuals who were diagnosed with COVID-19 and their family member or partner, adults aged 18 years or above who could read and understand English and who were able to give written consent and complete the questionnaire using an electronic device. Participants were excluded if they had not had COVID-19 or if they were $<18$ years of age.

\section{Survey development}

The survey included two QoL questionnaires: EuroQol group five dimensions three level (EQ-5D-3L; in this study, for simplicity throughout this manuscript, we refer to EQ-5D-3L as 'EQ-5D') and Family Reported Outcome Measure (FROM-16). There were additional sociodemographic questions such as responder's age, gender and country of residence (table 1). A pretest draft survey was piloted during May 2020 in 20 individuals without COVID-19 across several countries including the UK, India and the UAE. Views were also sought from the study research partners, two patients and one family member. The survey questions were revised based on the collective feedback.

\section{Patient and public involvement}

Two patients and one family member were involved as integral study research partners, one of whom ( $\mathrm{SJN}$ ) is a coauthor. They were involved in reviewing the study protocol, drafting the survey, reviewing the manuscript and providing suggestions from the patient and family perspective.

\section{Survey structure}

The survey had two sections. Section 1 was completed by the COVID-19 survivor. Each survivor provided basic demographic details and provided EQ-5D responses. Section 2 was completed by the partner or a family member of the survivor who provided basic demographic details and completed FROM-16. The survey did not specify whether this should be someone the patient lives with or whether it could be any close relation; however, the family member of the COVID-19 survivor was asked to specify their relationship to the patient.
Table 1 Sociodemographic characteristics of the study participants

\begin{tabular}{|c|c|c|}
\hline Variables & Categories & $\mathbf{N}(\%)$ or $\mathbf{N}(\mathrm{SD})$ \\
\hline \multicolumn{3}{|l|}{$\begin{array}{l}\text { COVID-19 survivors } \\
(n=735)\end{array}$} \\
\hline \multirow[t]{2}{*}{ Gender } & Male & $172(23.4 \%)$ \\
\hline & Female & $563(76.6 \%)$ \\
\hline \multirow[t]{4}{*}{ Age (years) } & Mean (SD) & $47.77(11.656)$ \\
\hline & Median & 48.00 \\
\hline & Range & $19-85$ \\
\hline & Range (IQR) & 19-85 (16) \\
\hline \multirow{7}{*}{$\begin{array}{l}\text { Number of weeks since } \\
\text { COVID-19 diagnosis }\end{array}$} & Mean (SD) & $12.76(6.104)$ \\
\hline & Median & 13.00 \\
\hline & Range & $1-36$ \\
\hline & Range (IQR) & $1-36(8)$ \\
\hline & $\geq 4$ weeks & $98(13.3 \%)$ \\
\hline & 5-11 weeks & $170(23.1 \%)$ \\
\hline & $\geq 12$ weeks & $467(63.5 \%)$ \\
\hline \multirow[t]{7}{*}{ Occupation } & Unemployed & $19(2.6 \%)$ \\
\hline & In paid work & $538(73.2 \%)$ \\
\hline & $\begin{array}{l}\text { In education or } \\
\text { training }\end{array}$ & $26(3.5 \%)$ \\
\hline & In unpaid work & $7(1 \%)$ \\
\hline & $\begin{array}{l}\text { Work in the home/ } \\
\text { manage the family }\end{array}$ & $60(8.2 \%)$ \\
\hline & Retired & $66(9 \%)$ \\
\hline & Rather not say & $19(2.6 \%)$ \\
\hline \multirow[t]{2}{*}{ Existing health conditions } & No & $508(69.1 \%)$ \\
\hline & Yes & 227 (30.9\%) \\
\hline \multirow[t]{2}{*}{ Hospitalised for COVID-19 } & No & 587 (79.9\%) \\
\hline & Yes & $148(20.1 \%)$ \\
\hline \multirow[t]{3}{*}{ Regions } & Europe & $372(50.6 \%)$ \\
\hline & North America & $283(38.5 \%)$ \\
\hline & Rest of the world & $80(10.9 \%)$ \\
\hline \multicolumn{3}{|l|}{ Family members ( $n=735$ ) } \\
\hline \multirow[t]{2}{*}{ Gender } & Male & $489(66.5 \%)$ \\
\hline & Female & $246(33.5 \%)$ \\
\hline \multirow[t]{3}{*}{ Age (years) } & Mean (SD) & $47.43(13.582)$ \\
\hline & Median & 48.00 \\
\hline & Range & $18-87$ \\
\hline \multirow[t]{6}{*}{ Occupation } & Unemployed & $42(5.7 \%)$ \\
\hline & In paid work & $530(72.1 \%)$ \\
\hline & $\begin{array}{l}\text { In education or } \\
\text { training }\end{array}$ & $29(3.9 \%)$ \\
\hline & In unpaid work & $18(2.4 \%)$ \\
\hline & Retired & 95 (12.9\%) \\
\hline & Rather not say & 21 (2.9\%) \\
\hline
\end{tabular}

Continued 


\begin{tabular}{lll} 
Table 1 Continued & & \\
\hline Variables & Categories & N (\%) or N (SD) \\
\hline $\begin{array}{l}\text { Relationship to the person } \\
\text { affected with COVID-19 }\end{array}$ & Spouse/Partner & $571(77.7 \%)$ \\
& Parents & $48(6.5 \%)$ \\
& Son/Daughter & $77(10.5 \%)$ \\
& Brother/Sister & $24(3.3 \%)$ \\
& Other & $15(2 \%)$ \\
Diagnosed with COVID-19 & No & $380(51.7 \%)$ \\
& Yes & $355(48.3 \%)$ \\
\hline
\end{tabular}

\section{Measurement tools}

The EQ-5D is a self-reported generic health-related QoL (HRQoL) instrument that specifically addresses health status. ${ }^{4}$ It consists of five questions on mobility, self-care, usual activities, pain and discomfort and anxiety and depression with 3-point response categories ( $1=$ no problems, $2=$ some problems and $3=$ serious or extreme problems). The EQ-visual analogue scale (VAS) component of EQ-5D asks respondents to rate their overall health status from 0 (worst imaginable health) to 100 (best imaginable health).

The FROM-16 measures the impact of a patient's disease on the QoL of a family member or partner of a patient. ${ }^{5}$ The FROM-16 comprises 16 items with 3-point response options for each: not at all (scoring 0 ), a little ${ }^{1}$ and a lot, ${ }^{2}$ with a total score range of $0-32$. The higher the score, the greater the negative impact on the family member's QoL. The 16 items are divided into two domains: emotional (6 items, maximum score 12) and personal and social life (10 items, maximum score 20). The FROM-16 has proven psychometric properties, a rapid completion time of 2 min $^{5}$ and translations are available in several languages. ${ }^{6}$ A generic measure, the FROM-16 has been validated across all areas of medicine $e^{5-7}$ and is therefore suitable for measuring the impact of COVID-19 on the partner and family members of those affected. As it is a generic measure, data generated can be compared with data from other medical conditions.

\section{Outcome}

The impact of COVID-19 on the quality of life of survivors and their partners and family members.

\section{Exposure}

COVID-19 infection of the participant or of the family member.

\section{Covariates}

The covariates included hospital stay due to COVID-19 infection, existing health condition of survivors, number of weeks since COVID-19 diagnosis, partners and family members diagnosed with COVID-19, family members' relationship to survivors, country of residence, age and sex of family members and survivors. All the covariates, including hospitalisation, existing conditions and number of weeks since COVID-19 diagnosis were based on self-report.

\section{Missing data}

There were no missing data, but two responses were ambiguous for one of the variables (EQ-VAS) and were excluded from the analysis.

\section{Statistical analysis}

Descriptive statistics (ie, mean, SD, median, IQR) were performed for all variables. The Shapiro-Wilk test was used to examine normal distribution of continuous variables. The required assumptions for normal distribution were not met. Consequently, data analysis employed non-parametric statistical method. Both the EQ-5D and the FROM-16 scores were treated in the analysis as dependent variables. The EQ-VAS component of EQ-5D was examined separately as a dependent variable. To determine differences between groups defined by each outcome, $\chi^{2}$ tests (when appropriate, Fisher's exact tests) and Mann-Whitney $\mathrm{U}$ tests were computed. These bivariate comparisons were based on COVID-19 survivor's characteristics (gender, existing health condition and hospitalisation) and family member characteristics (gender and whether diagnosed with COVID-19). Spearman's rank correlation coefficient and multiple regression analysis were conducted to understand the effect of independent variables (ie, predictors: survivor age, existing health condition, hospital stay for COVID19 , number of weeks since COVID-19 diagnosis, survivor gender) on the EQ-5D outcomes. Similarly, these analyses were conducted to understand the effect of independent variables (EQ-5D score, age family member, number of weeks since COVID-19 diagnosis, family member gender, whether family member also had COVID-19, relationship to survivor, survivor age, survivor existing health condition, survivor hospital stay for COVID-19) on the FROM-16 outcomes. Statistical Product and Service Solutions (V.25) was used and the probability of type I error was set at $\mathrm{p}<0.05$.

\section{RESULTS}

\section{Sociodemographic characteristics of the study participants}

A total of 1254 respondents consented to participate in the survey: 765 completed both sections. Thirty responses were excluded as the respondents were below the age of 18 years. The final analysis included 735 COVID-19 survivors and their family members/partner from Europe (50.6\%), North America $(38.5 \%)$ and the rest of the world $(10.9 \%)$ (table 1$)$.

Of the 735 COVID-19 survivors, $76.6 \%$ were females (mean and median age $=48$ years) and $73.3 \%$ were in paid employment. The mean time since COVID-19 symptoms started was 12.8 weeks (median $=13$ weeks). In $86.6 \%(\mathrm{n}=637),>4$ weeks had elapsed since COVID-19 symptoms started and in $63.5 \%(n=467)>12$ weeks had elapsed. Of the family members (mean age $=48$ years, 
Table 2 Mean scores of EQ-5D-3L and FROM-16 $(n=735)$

\begin{tabular}{|c|c|c|c|}
\hline Scale & Mean (SD) & $\begin{array}{l}\text { Median } \\
\text { (IQR) }\end{array}$ & Range \\
\hline \multicolumn{4}{|l|}{ EQ-5D-3L domains } \\
\hline Overall score & $8.65(1.97)$ & $9(3)$ & $6-14$ \\
\hline Mobility & $1.59(0.54)$ & $2(1)$ & $1-3$ \\
\hline Self-care & $1.23(0.45)$ & $1(0)$ & $1-3$ \\
\hline Usual activities & $2.06(0.68)$ & $2(1)$ & $1-3$ \\
\hline Pain/Discomfort & $1.93(0.56)$ & $2(0)$ & $1-3$ \\
\hline Anxiety/Depression & $1.84(0.67)$ & $2(1)$ & $1-3$ \\
\hline EQ-VAS $(\mathrm{n}=733)$ & $55.83(22.94)$ & $60(35)$ & $3-100$ \\
\hline \multicolumn{4}{|l|}{ FROM-16 } \\
\hline Overall score & $15.00(8.05)$ & $15(13)$ & $0-32$ \\
\hline Emotional domain & $6.12(3.23)$ & $6.0(5)$ & $0-12$ \\
\hline Worried & $1.43(0.61)$ & $1(1)$ & $0-3$ \\
\hline Angry & $0.75(0.73)$ & $1(1)$ & $0-3$ \\
\hline Sad & $1.05(0.70)$ & $1(1)$ & $0-3$ \\
\hline Frustrated & $1.24(0.74)$ & $1(1)$ & $0-3$ \\
\hline Talking about thoughts & $0.84(0.79)$ & $1(1)$ & $0-3$ \\
\hline Difficulty caring & $0.81(0.76)$ & $1(1)$ & $0-3$ \\
\hline $\begin{array}{l}\text { Personal and social } \\
\text { domain }\end{array}$ & $8.88(5.51)$ & $9.0(9)$ & $0-20$ \\
\hline Time for self & $0.74(0.76)$ & $1(1)$ & $0-3$ \\
\hline Everyday travel & $0.63(0.78)$ & $0(1)$ & $0-3$ \\
\hline Eating habits & $0.65(0.73)$ & $0(1)$ & $0-3$ \\
\hline Family activities & $1.26(0.73)$ & $1(1)$ & $0-3$ \\
\hline Holiday & $1.10(0.88)$ & $1(2)$ & $0-3$ \\
\hline Sex life & $1.09(0.85)$ & $1(2)$ & $0-3$ \\
\hline Work or study & $0.84(0.79)$ & $1(1)$ & $0-3$ \\
\hline Family relationship & $0.73(0.76)$ & $1(1)$ & $0-3$ \\
\hline Family expenses & $0.83(0.82)$ & $1(2)$ & $0-3$ \\
\hline Sleep & $1.01(0.79)$ & $1(2)$ & $0-3$ \\
\hline
\end{tabular}

EQ-5D-3L, EuroQol group five dimensions three level; FROM-16, Family Reported Outcome Measure; VAS, visual analogue scale.

median $=47$ years), $66.5 \%$ were male and $72.1 \%$ were in paid employment. Most of the family members were partners $(77.7 \%)$, followed by sons and daughters $(10.5 \%)$ and parents $(6.5 \%)$. In addition, $48.3 \%$ of the family members had also contracted COVID-19 (table 1).

\section{Quality of life impact of COVID-19 on survivors}

The overall EQ-5D mean score was $8.65(\mathrm{SD}=1.97)$ with the 'usual activities' item scoring the highest (mean $=2.06$, $\max =3$ ) followed by pain/discomfort (1.93) and anxiety/ depression (1.84). The mean score of the visual analogue part of $\mathrm{EQ}-5 \mathrm{D}$ was $56(\mathrm{SD}=22.94)$ (table 2).

Of the five dimensions of EQ-5D, 'pain and discomfort' was the impact most frequently reported $(81.1 \%$; $68.7 \%$ some problems and $12.4 \%$ extreme problems), followed by usual activities $(79.5 \% ; 53.2 \%$ and $26.3 \%)$ and anxiety and depression (68.7\%; 53.3\% and $15.4 \%$ ) (figure 1). There was a significant gender difference for 'mobility' and for 'pain and discomfort' $(\mathrm{p} \leq 0.05)$ with females being more impacted than males (table 3 ).

Although existing health conditions were self-reported and severity was not stated, survivors with existing health conditions did not appear to differ from those without such conditions except for mobility and usual activities $(p \leq 0.05)$ (table 3$)$. Having an existing health condition was not a clear predictor of impact on the family member/partner's QoL. There was a significant difference between the survivors who had been hospitalised for COVID-19 (20\%) and those who had not, with the hospitalised survivors being more severely affected across mobility, self-care $(\mathrm{p} \leq 0.001)$ and usual activities $(\mathrm{p} \leq 0.02)$ (table 3).

There were significant differences in overall EQ-5D mean scores between survivors with respect to number of weeks since COVID-19 diagnosis $(p<0.001)$. The overall EQ-5D mean scores of survivors having COVID-19 symptoms for up to 4 weeks was 8.03 ( $\mathrm{SD}=1.97$ ), 5-11 weeks was $8.3(\mathrm{SD}=2.13)$ and 12 weeks and above was $8.9(\mathrm{SD}=1.86)$.

\section{Quality of life impact of COVID-19 on family members}

The overall FROM-16 mean score was 15, reflecting the extent of the impact of the survivors' COVID-19 on the HRQoL of their family members (table 2). The mean score of each of the 16 items is given in table 2 with 'feeling worried' scoring highest (1.46) followed by family activities, frustration, holiday and sex life (1.26, 1.24, 1.10 and 1.09 , respectively) (table 2). Of the FROM-16 items, the feeling of being worried was most frequently reported $(93.6 \%$; $44.6 \%$ a little, $49 \%$ a lot $)$, followed by family activities $(83.3 \%$; $41 \%, 42.3 \%)$, feeling of frustration $(81.7 \%$; $39.7 \%, 42 \%)$, feeling sad $(78.4 \% ; 51.2 \%, 27.2 \%)$, sleep $(68.9 \% ; 37.1 \%, 31.8 \%)$ and sex life $(68.1 \% ; 26.7 \%$, $41.4 \%$ ) (figure 2).

There was a significant gender difference among family members, with females feeling more sad, experiencing more impact on everyday travel $(\mathrm{p} \leq 0.01)$ and on their sleep $(p \leq 0.05)$. The impact on sex life was experienced significantly more by males than females $(p \leq 0.001)$ (table 4).

Those with a COVID-19 history experienced a greater impact on eating habits, work and study, family activities, holiday $(p \leq 0.05)$, sex life and sleep $(p \leq 0.001)$. There were no significant differences for the remaining 10 items of FROM-16 (table 4).

There were significant differences in overall FROM-16 mean scores between family members of survivors with respect to onset of COVID-19 symptoms $(\mathrm{p}<0.01)$. The overall FROM-16 mean scores of family members of survivors having COVID-19 symptoms for up to 4 weeks was $16.11(\mathrm{SD}=7.35), 5-11$ weeks was $13.31(\mathrm{SD}=7.77)$ and 12 weeks and above was $15.38(\mathrm{SD}=8.21)$.

Relationship between the quality of life of survivors and their family members

There were significant positive correlations between the EQ-5D score and the survivors' gender, hospital stay, existing 


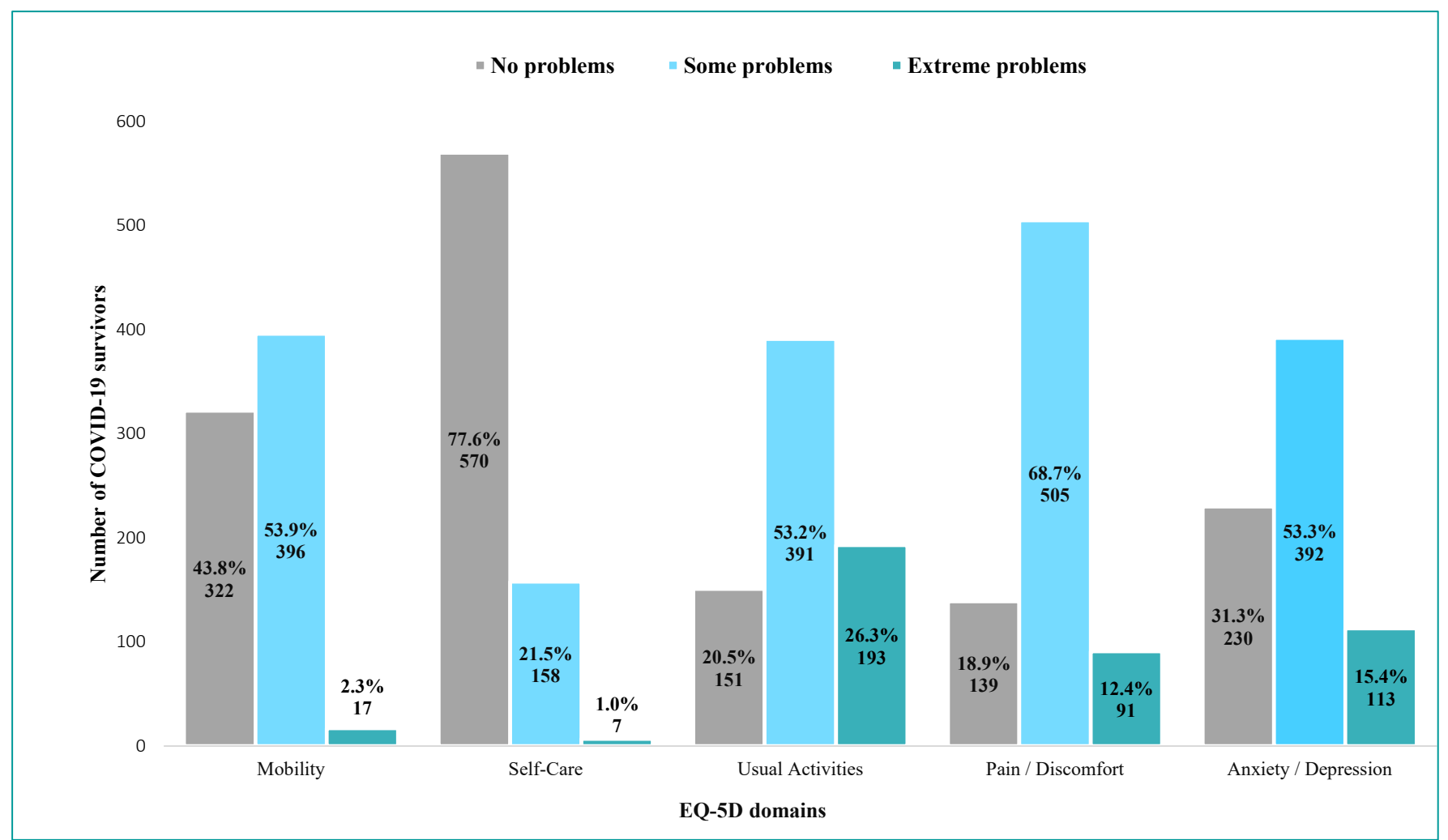

Figure 1 COVID-19 survivor response to EuroQol group five dimensions three level (EQ-5D-3L) ( $n=735)$.

health condition and number of weeks since COVID-19 diagnosis $(\mathrm{p}<0.05, \mathrm{p}<0.001)$ (table 5$)$.

There was a significant positive association between the family members' FROM-16 scores and the survivors' EQ-5D scores $(\mathrm{p}<0.001)($ table 5) and a significant negative association between FROM-16 scores and the family members' age, survivors' age and EQ-VAS scores $(\mathrm{p}<0.05)$.

The EQ-VAS scores showed a significant inverse relationship with EQ-5D $(\mathrm{p}<0.01)$. However, other variables such as hospital stay, existing health condition and gender (being female) were associated with lower EQ-VAS scores $(p<0.05)$, that is, lower health status (table 5).

\section{Can quality of life predict outcomes?}

The results of multiple regression analyses indicated that survivors' demographics, number of weeks since COVID-19 diagnosis and hospital stay were significant predictors of the extent of impact on QoL of the survivor $(\mathrm{p}=0.001$ ) while the survivors' existing health condition was not a predictor (table 6). Inclusion of variables such as EQ-5D scores, family members' COVID-19 history, family members' gender and relationship to the survivor in the model predicted family reported outcomes $(\mathrm{p}=0.001)$ while family members' age, survivors' age, number of weeks since COVID-19 diagnosis,

Table 3 Comparisons $†$ of EQ-5D-3L scores for gender, existing health condition and hospitalisation

\begin{tabular}{|c|c|c|c|c|c|c|c|c|c|}
\hline \multirow[b]{2}{*}{ EQ-5D-3L domain } & \multicolumn{2}{|l|}{$\begin{array}{l}\text { Gender } \\
\text { Mean score }\end{array}$} & \multirow[b]{2}{*}{$P$ value } & \multicolumn{2}{|c|}{$\begin{array}{l}\text { Existing health condition } \\
\text { Mean score }\end{array}$} & \multirow[b]{2}{*}{$P$ value } & \multicolumn{2}{|c|}{$\begin{array}{l}\text { Hospitalised for COVID-19 } \\
\text { Mean score }\end{array}$} & \multirow[b]{2}{*}{$P$ value } \\
\hline & Male $(n=172)$ & Female $(n=563)$ & & Yes $(n=227)$ & No $(n=508)$ & & Yes $(n=148)$ & No $(n=587)$ & \\
\hline Mobility & 1.51 & 1.61 & $0.037^{\star}$ & 1.67 & 1.55 & $0.006^{\star *}$ & 1.75 & 1.54 & $0.0001^{* *}$ \\
\hline Self-care & 1.22 & 1.24 & 0.602 & 1.28 & 1.21 & 0.053 & 1.36 & 1.20 & $0.0001^{* *}$ \\
\hline Usual activities & 1.97 & 2.08 & 0.065 & 2.14 & 2.02 & $0.034^{*}$ & 2.19 & 2.02 & $0.009^{\star *}$ \\
\hline Anxiety/Depression & 1.81 & 1.85 & 0.611 & 1.88 & 1.82 & 0.289 & 1.88 & 1.83 & 0.427 \\
\hline
\end{tabular}

${ }^{* \star} p \leq 0.05,{ }^{* \star} p \leq 0.01$. (P- values were calculated using mean rank scoresbut mean scores are presented here for ease of understanding). †Mann-Whitney U test.

EQ-5D-3L, EuroQol group five dimensions three level. 


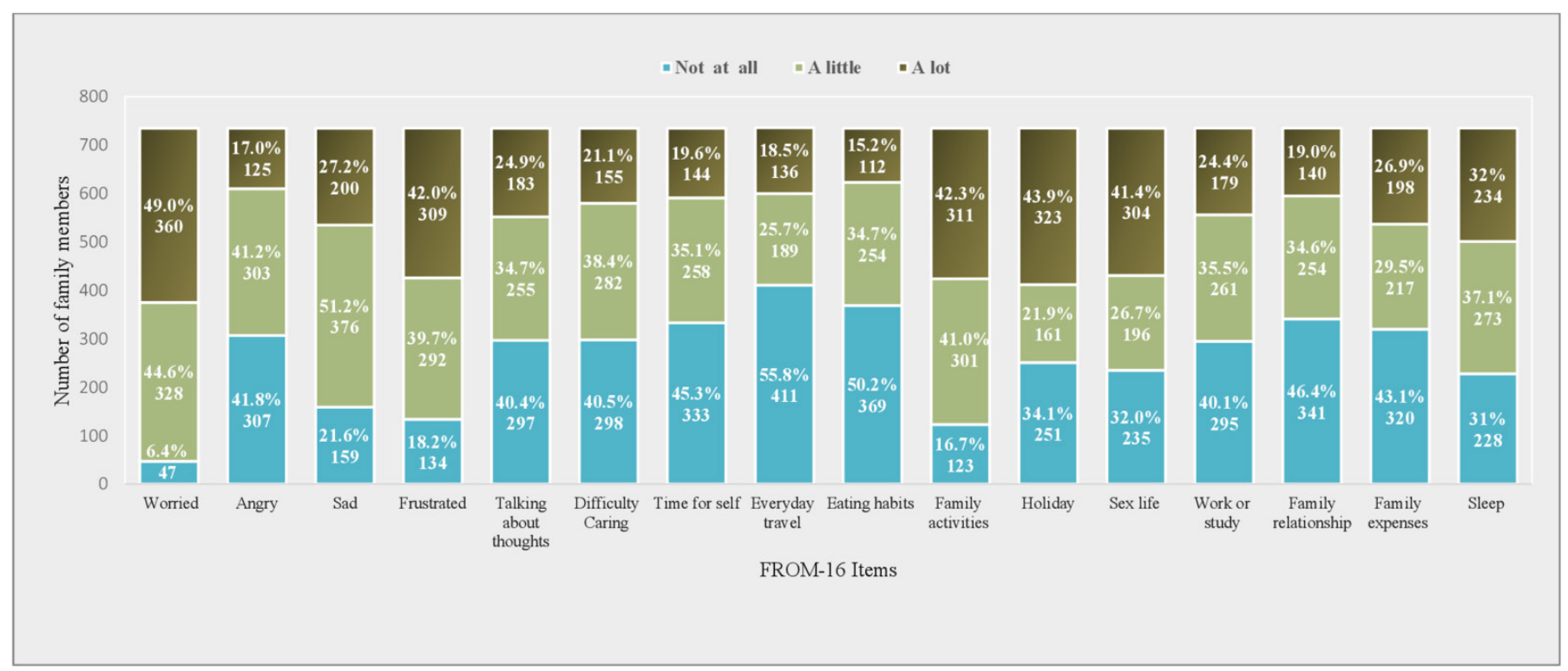

Figure 2 Partner and family member response to Family Reported Outcome Measure (FROM-16) items ( $n=735)$.

existing health condition and hospital stay were not significant predictors of QoL of family members (table 7). The multiple regression analyses confirmed that the QoL of family members / partner was more impacted than survivors, female family members were affected more than males, family members with a history of COVID-19 were affected more than those without and partners were affected substantially more than those of other relationships. In addition, the model predicted that younger survivors' functional behaviour (both physical and psychosocial) was more impacted by COVID-19.

\section{DISCUSSION}

This study fills an important knowledge gap in measuring the impact of COVID-19 on the HRQoL of both the

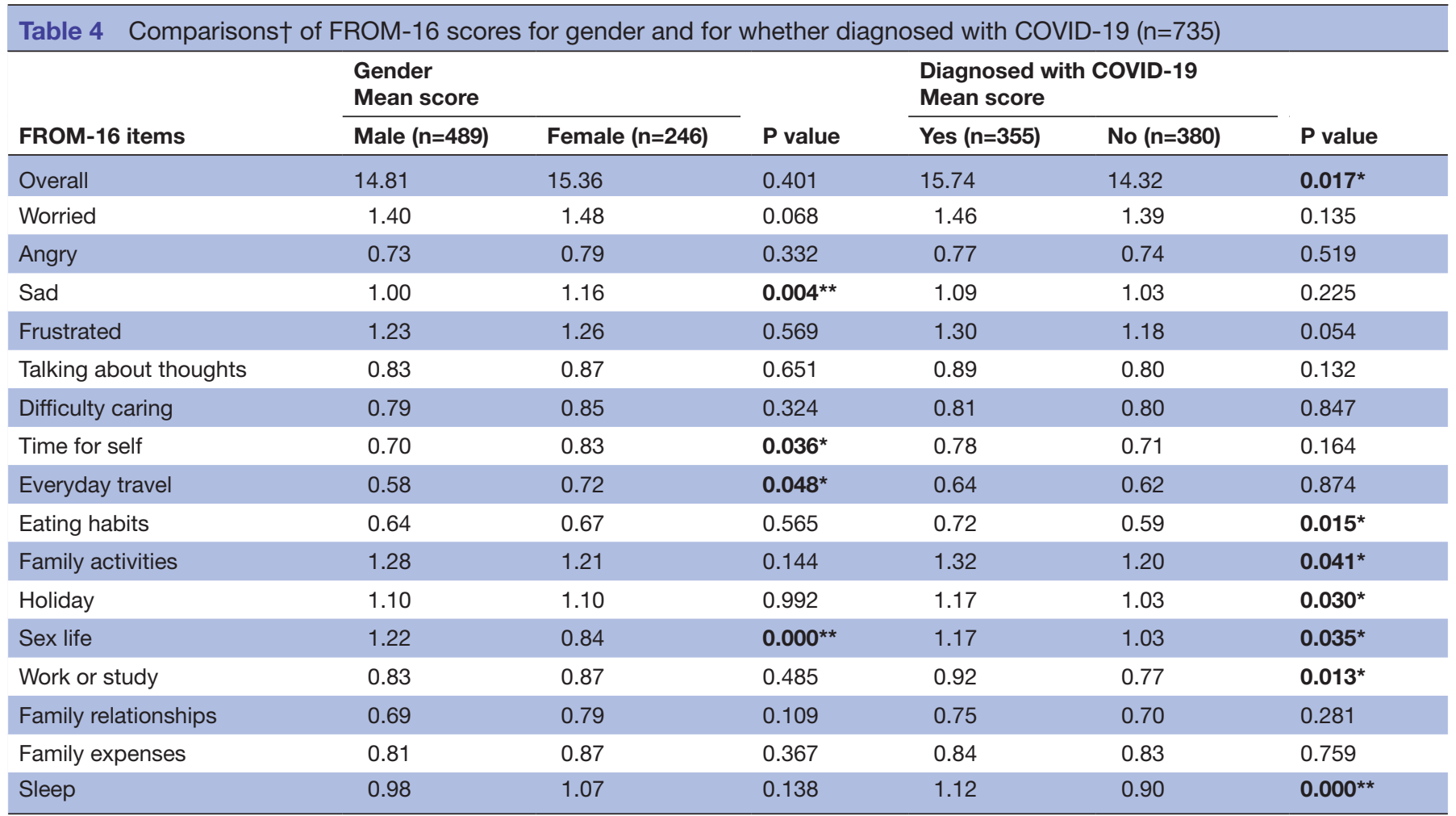

${ }^{*} p \leq 0.05,{ }^{* *} p \leq 0.01$. (P values were calculated using meanrank scores but mean scores are presented here for ease of understanding). †Mann-Whitney U test.

FROM-16, Family Reported Outcome Measure. 


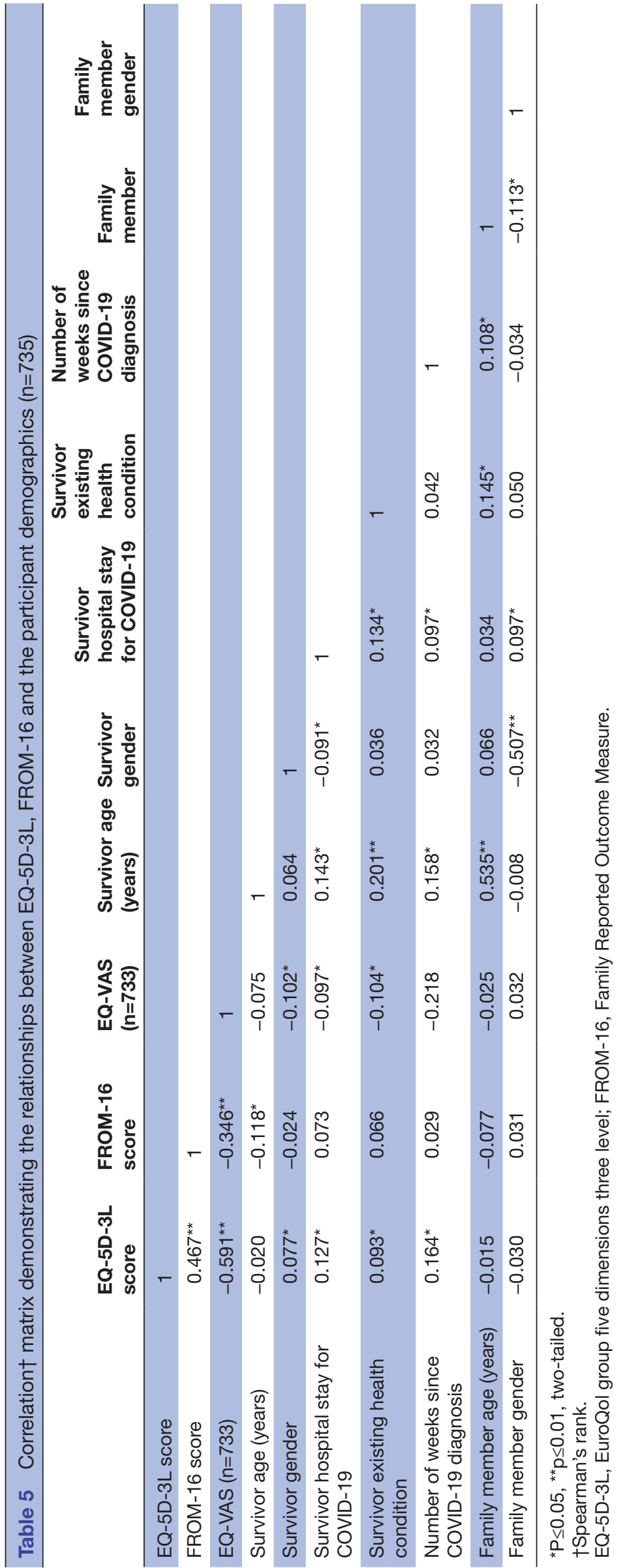

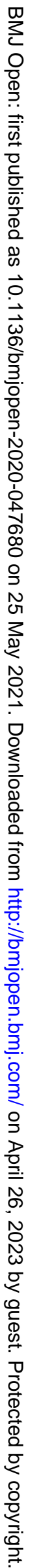


Table 6 Summary of survivors' characteristics predicting EQ-5D-3L scores* $(n=735)$

\begin{tabular}{|c|c|c|c|c|c|c|c|c|c|c|}
\hline \multirow[b]{2}{*}{ Predictor } & \multicolumn{2}{|c|}{$\begin{array}{l}\text { Unstandardised } \\
\text { coefficients }\end{array}$} & \multicolumn{2}{|c|}{$\begin{array}{l}\text { Standardised } \\
\text { coefficients }\end{array}$} & \multicolumn{2}{|c|}{$\begin{array}{l}95 \% \mathrm{Cl} \text { levels } \\
\text { for B }\end{array}$} & \multirow[b]{2}{*}{$\mathbf{R}^{2}$} & \multirow[b]{2}{*}{$\begin{array}{l}\text { Adjusted } \\
\mathbf{R}^{2}\end{array}$} & \multirow[b]{2}{*}{ F-test } & \multirow[b]{2}{*}{ P value } \\
\hline & B & SE & Beta & $P$ value & $\begin{array}{l}\text { Lower } \\
\text { level }\end{array}$ & $\begin{array}{l}\text { Upper } \\
\text { level }\end{array}$ & & & & \\
\hline & & & & & & & 0.058 & 0.051 & 8.907 & 0.0001 \\
\hline Survivor age & -0.013 & 0.006 & -0.076 & 0.043 & -0.025 & 0.000 & & & & \\
\hline Existing health condition & 0.298 & 0.157 & 0.070 & 0.059 & -0.011 & 0.607 & & & & \\
\hline $\begin{array}{l}\text { Number of weeks since COVID-19 } \\
\text { diagnosis }\end{array}$ & 0.050 & 0.012 & 0.154 & 0.0001 & 0.027 & 0.073 & & & & \\
\hline Male gender & -0.471 & 0.169 & -0.101 & 0.005 & -0.802 & -0.139 & & & & \\
\hline
\end{tabular}

${ }^{*}$ Multiple regression; $\mathrm{B}=$ the slope of the line between the predictor variable and the dependent variable - the larger the number, the more spread out the points are from the regression line; F-test=degree of the linear regression model fitting the data; $R^{2}=$ how well the model fits the data; males $=1$ and females $=0$; females are the reference group.

EQ-5D-3L, EuroQol group five dimensions three level.

survivors and, importantly, their partners and family members. HRQoL is defined as a person's perception of his/her physical, mental, social and overall well-being. ${ }^{89}$ Therefore, its assessment embraces a wider view of the impact of COVID-19.

This study has revealed that the pandemic has a major impact on lives of those who have survived the infection. The survey depended on the patient's self-report of the diagnosis of COVID-19 infection and did not specifically ask whether patients had had a COVID-19-positive test. However, further authentication of the diagnosis was given by both the patient and their relative having answered the survey. Pain and discomfort were the most frequently reported problem by COVID-19 survivors, followed by impact on their usual activities, anxiety and depression, affecting females to a greater extent. As the majority of COVID-19 survivors were in paid employment, being physically unwell might have impacted their usual activities or return to work. According to a review on return to work after critical illness, ${ }^{10}$ globally, a third of previously employed survivors after intensive care stays remained out of work after 5 years.

In the survey, COVID-19 survivors were asked whether they were 'already suffering from some existing chronic health condition (such as diabetes, heart disease, lung disease)' prior to the infection with COVID-19. Survivors with existing health conditions did not differ significantly from those without such conditions except for mobility and usual activities however, having an existing health condition was not a significant predictor of impact on the family member/partner's QoL. The survivor's QoL was impacted greatly irrespective of having a existing health condition as it was not clear predictor of EQ-5D scores in regression analysis. Hospitalised survivors reported greater impact on mobility, self-care and usual activities compared with those who had not been hospitalised. This survey did not ask respondents whether those hospitalised were admitted to intensive care unit (ICU). So we are not able to draw any conclusion concerning the relationship of admission to ICU to later QoL.

The study also revealed a major impact on QoL of the survivors' partners and family members with partners being most impacted. Currently, Minimal Clinically Important Difference (MCID) for FROM-16 has not been published; however, MCID values for such questionnaires usually are approximately $10 \%-20 \%$ of the total score range, and so we would expect the FROM-16 MCID to be approximately $3-6$. If this is the case, the statistically significant differences reported would also be clinically significant. Nearly half of participating partners and family members also reported having had COVID-19. Although there were no significant differences between the family members with COVID-19 and those without across 10 of the 16 QoL items of FROM-16, eating habits, family activities, holiday, sleep, sex life and work or study were impacted significantly more in those who had had COVID-19. Overall, FROM-16 scores were higher for partners and family members with COVID-19 after adjusting for age, gender, relationship to survivor and the overall survivors' EQ-5D scores, thus indicating poorer QoL for family members with COVID-19 than for those without.

Most partners and family members reported being worried and frustrated, many reported sadness, inability to talk to someone and difficulty in caring for their loved ones. This is not surprising in a situation with constant media coverage with emphasis on high daily death rates, the fear of infecting loved ones, stigma due to community or family members blaming survivors for the spread of the illness, isolation of loved ones, inability of a family member to provide support and prolonged recovery time. ${ }^{11}$ Such stressors have been implicated in the poor psychological and emotional health of survivors and their family members. ${ }^{11-14}$

Family members reported an impact on sexual life as a result of their relative's COVID-19 and this impact was higher in males and in family members who has also 


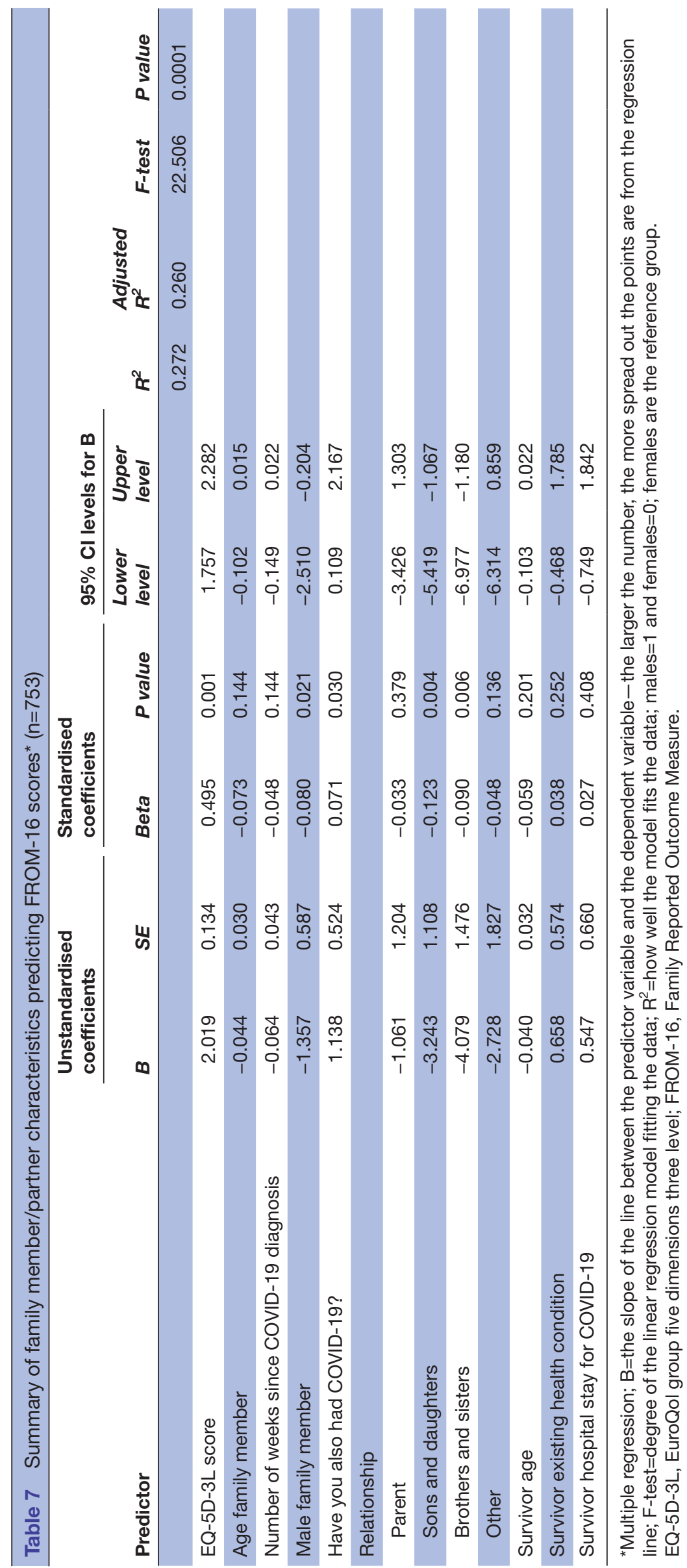

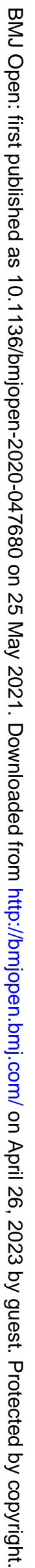


contracted COVID-19. Two-thirds of family members were either spouses or partners, who could have experienced these difficulties because of the contagious nature of COVID-19 and because of postsurvival symptoms. Moreover, physical illness in partners has a significant impact on marital relationships, contributing to marital dissatisfaction and likelihood of later divorce. ${ }^{15}$ Over half of partners and family members reported impact on holidays and nearly half reported an increase in expenses due to their relative's COVID-19.

One of the key findings of this study is the evidence that in survivors in whom the COVID-19 onset was $>12$ weeks ago, there was still a major persisting impact on QoL across all domains in both survivors and family members. This provides further evidence of the severe impact of post-acute COVID-19 ('long COVID-19') and 'chronic COVID-19'. ${ }^{16}$ According to the National Institute for Health and Care Excellence, the term 'long COVID-19' 'is commonly used to describe signs and symptoms that continue or develop after acute COVID-19. It includes both ongoing symptomatic COVID-19 (from 4 to 12 weeks) and post-COVID-19 syndrome (12 weeks or more) '. ${ }^{17}$ The term 'persisting' refers to the continuity of the impact of COVID-19 on survivor's health since the onset of COVID-19 infection.

Interestingly, of the patients who participated, most $(76.6 \%)$ were women, as found in other surveys ${ }^{18}$; however, there was a higher proportion of men among participating family members $(66.5 \%)$. This may be because the majority of COVID-19 social media support groups have been initiated by women (patients), and the most convenient family person to ask to participate might be their partners (mostly male).

\section{Comparison with other studies}

Chinese survivors of COVID-19 reported lower HRQoL with significant impact on their physical and psychological health, 1 month after recovery. ${ }^{19}$ Our study has shown a major impact on the HRQoL of survivors of COVID-19 and on their partners and family members. This is consistent with the findings of Golics $e t a l^{20}$ that multiple elements of family members' lives can be affected by a relative's illness including emotional, financial, family relationships, education and work, leisure time, and social activities.

Our study has shown that most $(87 \%)$ survivors had COVID-19 for $>4$ weeks, and $64 \%>12$ weeks indicating that survivors continued to remain unwell for long periods of time, due to postviral symptoms or 'long COVID-19'. This is in contrast to a UK COVID-19 symptom study, ${ }^{21}$ where only $10 \%$ of COVID-19-positive survivors remained unwell at 3 weeks, and a small proportion for $>3$ months. An online survey of British doctors in August 2020 revealed that many were being treated for long-term COVID-19 symptoms such as chronic fatigue, muscle weakness, loss of sense of smell and concentration difficulties. ${ }^{22}$

In our study, 69\% COVID-19 survivors reported feelings of anxiety and depression, much higher than the
$43.1 \%$ reported by $\mathrm{Ma}$ et $a t^{\dagger}$ in clinically stable patients with COVID-19. Previous studies of SARS revealed the persistence of depression in patients up to 30 months after discharge from hospital. ${ }^{2324}$

Several studies have shown the impact of COVID-19 on sleep patterns of survivors, with an increase in prevalence of insomnia. ${ }^{25-27}$ We do not know whether the sleep patterns of survivors in our study were also impacted, since EQ-5D does not include such an item. However, in our study $69 \%$ of partners and family members experienced problems with sleep, and $32 \%$ reported that their sleep was impacted 'a lot'.

The domain mean scores for FROM-16 in this study were 6.1 (emotional) and 8.9 (personal and social life), which are higher than the mean domain scores reported by Golics et at (emotional=5.6; personal and social life=6.7) on the impact of patients' chronic disease on family members across 26 medical specialties. Another study ${ }^{4}$ reported the mean domain scores of family members of patients with cancer as emotional $=4.7$ and personal and social life $=7.1$. In a FROM-16 study on family members of patients with urinary stone disease, family members were not impacted much by their relative's disease, however they reported a slightly greater degree of change in the 'emotional' domain compared with the 'personal and social life' domain. ${ }^{28}$ This indicates that family members of COVID-19 survivors suffered more than family members of patients with other severe chronic diseases.

\section{Strengths and limitations}

This study to our knowledge is the first global study to explore the impact of COVID-19 on both survivors and also their family members/partner. Other strengths include the large sample size, heterogenous population and use of validated tools to assess QoL impact. The study has demonstrated use of the FROM-16 questionnaire for studying the effects of a pandemic on family members of an infected person.

This study has several limitations. First, it suffers from considerable selection bias as only those COVID-19 survivors and family members who could access the internet and were active on social media completed the online questionnaires, limiting generalisability of the study findings. It is also possible that people who experienced persisting symptoms may have been more likely to have participated in the study. This survey was conducted internationally in the English language. Although FROM-16 is available to researchers in several languages, our full survey documents and the participant information sheet were only available to the participants in the English language, and in the survey FROM-16 was also only provided in English. Participants could only take part if they could understand all of the documentation. The ability of some respondents to read and understand English may have been limited, but we are not able to assess this. However, during the development of, in particular, FROM-16, the following issues were considered as part of its conceptualisation and development in order to improve its 
universality and translatability: (1) applying readability to the level of understanding of a 12-year old; (2) formatting of the items into short and complete sentences of about six words to enhance clarity of meaning; (3) ensuring ease of understanding to allow future cross-cultural adaptation, facilitating universality and translatability. Although we did not develop the EQ-5D, that questionnaire was also designed to be as universally understandable as possible. Concerning the wider survey questions, we took several steps in the development of the survey to ensure maximum comprehensibility: (1) we ensured that the readability was acceptable to a 12-year old standard; (2) we carried out an international pilot including participants for whom English was not their first language and made adjustments accordingly; (3) the survey was reviewed by our patient study research partners.

Second, the study, being cross-sectional, cannot establish causal relationships among the study variables. Because of the nature of the study, we could not collect any baseline measurements (pre-COVID-19 measurements). We are, therefore, not able to differentiate between the effect of COVID-19 infection or of a preexisting physical or mental state. However, only $30.9 \%$ of respondents had any existing health condition, and therefore this limitation only refers to this small proportion of respondents. In addition, as all the covariates in the study were self-reported, data on hospitalisation and medical problems could be inaccurate and is a potential limitation. ${ }^{29}$ This study does not have a control group but in healthy volunteers in the UK, mean EQ-5D scores were $\mathrm{EQ-VAS}=82.75$, mobility $=0.18$, self-care $=0.04$, usual activity $=0.16$, pain/discomfort $=0.33$, anxiety/depression $=0.20 .^{30}$ In contrast, COVID-19 survivors $(47.1 \%$ of survey respondents were from the UK) in our study had mean scores of $\mathrm{EQ-VAS}=55.83$, mobility $=1.59$, selfcare $=1.23$, usual activity $=2.06$, pain $/$ discomfort $=1.93$, anxiety/depression $=1.84$. This suggests that overall HRQoL was highly impaired in the COVID-19 survivors across all domains. Furthermore, the study was carried out between June and August 2020 when the severity of the pandemic varied among different countries. Therefore, the study results may have been influenced by the specific local and governmental measures in place at the time. It is likely that participants will have been living under different government restrictions, thereby possibly influencing responses to the questionnaires. However, because of the complexity of the international situation, we are not able to account for this. Although formal cultural adaptation of the survey questionnaire was not carried out, we endeavoured to ensure maximum understandability and acceptability. It should be noted that the questions asked are mostly universal in nature and do not refer to culturally specific practices such as semantic differences. However, despite these limitations, the study has provided a rapid overview of survivors' and their family members' HRQoL and revealed evidence of the substantial persisting effect on QoL of survivors and a major secondary impact on the lives of partners and family members. This information can be used to inform policymakers about the health needs of these individuals and may encourage the development of tailor-made support services.

\section{Implications for clinicians and policymakers}

Our results have shown how the impact of COVID-19 on one family member can have a domino effect on other family members, especially those close to them such as partner, parents and children. It is important to understand the needs of these impacted family members and survivors to ensure the overall well-being of the family unit. Based on the findings of this study, policymakers should consider developing and commissioning the following support services for survivors and family members:

- Post COVID-19 clinics: survivors reported pain and discomfort even after 12 weeks of COVID-19, indicating that tailored services to deal with such symptoms are important to help survivors suffering with long term sequelae. Survivors with post-COVID-19 complications should be heard and treated. Although such clinics have been started in a few countries, there is a considerable need for such initiatives globally.

- Needs-based mental health counselling: most family members and survivors reported being depressed and worried. It is imperative to further develop care services to ensure the mental well-being of survivors and their family members.

- Physical activity and rehabilitation services: most survivors have reported pain and discomfort and an inability to do their normal activities. Rehabilitation clinics could provide emotional and physical support to physically and emotionally drained survivors and their family members to enable their return to normal routines.

- Social support services: patients with COVID-19 are from diverse backgrounds and therefore will benefit from culturally and socially appropriate support. Financial assistance is particularly important for those who do not have health insurance to cover COVID-19 expenses.

- Patient support groups/local support groups for COVID-19 survivors and family members: local support groups could be used in primary care settings and can help by significantly combating isolation and the disability the study has identified that occurs in COVID-19 survivors and their family members/partners. This could in turn have health economic benefits by possibly reducing long-term utilisation of mental health services. Similar approaches have been successful, for example, in supporting people with myalgic encephalitis.

\section{Future research and recommendations}

Although this study provided an overview of the impact of COVID-19 on survivors' partners and family members, it was not designed to identify causal relationship. Future longitudinal studies are needed to understand the longterm impact of COVID-19. As COVID-19 is still a major challenge, with people experiencing 'long COVID-19', 
there is a need for further research including long-term studies to better understand 'long COVID-19' and its impacts on survivors and family members. However, the way the participants were recruited for the current study does not allow us to have access to follow-up data from this cohort. We were unable to measure the impact of COVID-19 on sleep and sex life of survivors, future studies should measure such impacts.

\section{CONCLUSION}

Survivors of COVID-19 report a major persisting impact on their QoL with many feeling unwell beyond 12 weeks. This indicates a demand for a holistic support system that is sensitive to their needs. Moreover, the QoL of partners and family members is also severely impacted, demonstrating the importance of investigating disease impact on family QoL. The establishment of services to provide support to family members of survivors and patients in general is therefore a key consideration in the future management of COVID-19. Although the recruitment method used inevitably leads to some degree of selection bias which in turn may dilute the generalisability of the study findings, the central conclusions of this study that COVID-19 has a profound and long-lasting impact on survivors and their family members continue to remain valid.

Acknowledgements We are grateful to all the COVID-19 survivors and family members/partners who participated in this study. We are grateful to the other 'patient and family research' study partners, Helen Allen and Marie Nixon, for their invaluable contribution.

Contributors RS primarily carried out the study, wrote first drafts and revised all documentation. SMS and AYF equally contributed to the design and supervision of the study and revised all study documentation and the manuscript. FA, JRI and SJN provided advice during the study and helped revise study documentation. FA, JRI and SJN reviewed the manuscript. The corresponding author attests that all listed authors meet authorship criteria and that no others meeting the criteria have been omitted.

Funding The authors have not declared a specific grant for this research from any funding agency in the public, commercial or not-for-profit sectors.

Competing interests RS and SJN declared no competing interest, AYF is joint copyright holder of FROM-16 and of other quality of life measures. AYF reports personal fees from Novartis. SMS is joint copyright holder of FROM-16 and of other quality of life measures. JRI reports personal fees from UCB Pharma, personal fees from Novartis, personal fees from Boehringer Ingelheim, personal fees from Kymera Therapeutics, personal fees from Viela Bio, personal fees from UpToDate, personal fees from Editor of British Journal of Dermatology, outside the submitted work; in addition, JRI is co-copyright holder of the Hidradenitis Suppurativa Quality of Life (HiSQOL) score. FA reports grants and personal fees from Janssen, personal fees from AbbVie, personal fees from Lilly Pharmaceuticals, personal fees from L'Oreal, personal fees from LEO Pharmaceuticals, personal fees from UCB, outside the submitted work.

Patient and public involvement Patients and/or the public were involved in the design, or conduct, or reporting, or dissemination plans of this research. Refer to the 'Methods' section for further details.

Patient consent for publication Not required.

Ethics approval Ethics approval was granted by the Cardiff University School of Medicine Research Ethics Committee (SMREC 20/60).

Provenance and peer review Not commissioned; externally peer reviewed.

Data availability statement All data relevant to the study conclusions are included in the article. Other data relevant to the study will be provided upon reasonable request by contacting the study author.
Open access This is an open access article distributed in accordance with the Creative Commons Attribution Non Commercial (CC BY-NC 4.0) license, which permits others to distribute, remix, adapt, build upon this work non-commercially, and license their derivative works on different terms, provided the original work is properly cited, appropriate credit is given, any changes made indicated, and the use is non-commercial. See: http://creativecommons.org/licenses/by-nc/4.0/.

ORCID iDs

Rubina Shah http://orcid.org/0000-0001-8158-712X

Faraz M Ali http://orcid.org/0000-0002-4184-2023

John R Ingram http://orcid.org/0000-0002-5257-1142

Sam M Salek http://orcid.org/0000000246125699

Andrew Y Finlay http://orcid.org/0000000321431646

\section{REFERENCES}

1 Holmes EA, O'Connor RC, Perry VH, et al. Multidisciplinary research priorities for the COVID-19 pandemic: a call for action for mental health science. Lancet Psychiatry 2020;7:547-60.

2 Golics CJ, Basra MKA, Salek MS, et al. The impact of patients chronic disease on family quality of life: an experience from 26 specialties. Int J Gen Med 2013;6:787-98.

3 Jisc. Online surveys. Jisc, Bristol, UK, 2020. Available: https://www. onlinesurveys.ac.uk/

4 EQ-5D-3L. User guide, 2018. Available: https://euroqol.org/ publications/user-guides

5 Golics CJ, Basra MKA, Finlay AY, et al. The development and validation of the Family Reported Outcome Measure (FROM-16)@ to assess the impact of disease on the partner or family member. Quality of Life Research 2014;23:317-26.

6 FROM-16. amily Reported Outcome Measure [Online], 2020. Available: https://www.cardiff.ac.uk/medicine/resources/quality-oflife-questionnaires/family-reported-outcome-measure

7 Chantarasap P, Johns NP, Pairojkul S, et al. Validation of the Thai version of the family reported outcome measure (FROM-16)(C) to assess the impact of disease on the partner or family members of patients with cancer. Health Qual Life Outcomes 2019;17:32.

8 Papakostas Gl, Petersen T, Mahal Y, et al. Quality of life assessments in major depressive disorder: a review of the literature. Gen Hosp Psychiatry 2004;26:13-17.

9 Ma Y-F, Li W, Deng H-B, et al. Prevalence of depression and its association with quality of life in clinically stable patients with COVID-19. J Affect Disord 2020;275:145-8.

10 Kamdar BB, Suri R, Suchyta MR, et al. Return to work after critical illness: a systematic review and meta-analysis. Thorax 2020;75:17-27.

11 Sahoo S, Mehra A, Suri V, et al. Lived experiences of the corona survivors (patients admitted in COVID wards): a narrative real-life documented summaries of internalized guilt, shame, stigma, anger. Asian J Psychiatr 2020;53:102187.

12 Tansey CMet al. One-Year outcomes and health care utilization in survivors of severe acute respiratory syndrome. Arch Intern Med 2007:167:1312-20.

13 Li Q, Guan X, Wu P, et al. Early transmission dynamics in Wuhan, China, of novel Coronavirus-Infected pneumonia. New England Journal of Medicine 2020;382:1199-207.

14 Xiang Y-T, Yang Y, Li W, et al. Timely mental health care for the 2019 novel coronavirus outbreak is urgently needed. The Lancet Psychiatry 2020;7:228-9.

15 Daniel K, Wolfe CDA, Busch MA, et al. What are the social consequences of stroke for Working-Aged adults? Stroke 2009;40:e431-40.

16 Greenhalgh T, Knight M, A'Court C, et al. Management of post-acute covid-19 in primary care. BMJ 2020;13:m3026.

17 NICE. Overview | COVID-19 rapid guideline: managing the long-term effects of COVID-19 | guidance, 2020.

18 Davis HE, Assaf GS, McCorkell L, et al. Characterizing long COVID in an international cohort: 7 months of symptoms and their impact. medRxiv 2020;2020:12.24.20248802.

19 Chen K-Y, Li T, Gong F-H, et al. Predictors of health-related quality of life and influencing factors for COVID-19 patients, a follow-up at one month. Front Psychiatry 2020;11.

20 Golics CJ, Basra MKA, Finlay AY, et al. The impact of disease on family members: a critical aspect of medical care. J R Soc Med 2013;106:399-407

21 COVID Symptom Study. How long does COVID-19 last? kings College London, 2020. Available: https://covid.joinzoe.com/post/ covid-long-term?fbclid=IwAR1RxIcmmdL-EFjh_al- 
22 Rimmer A. Covid-19: impact of long term symptoms will be profound, warns BMA. BMJ 2020;370:m3218.

$23 \mathrm{KK} \mathrm{W}$, Chan SK, TM M, et al. Anxiety, and depression in survivors of severe acute respiratory syndrome (SARS). J Trauma Stress 2005;18:39-42.

24 Mak IWC, Chu CM, Pan PC, et al. Long-Term psychiatric morbidities among SARS survivors. Gen Hosp Psychiatry 2009;31:318-26.

25 Fu W, Wang C, Zou L, et al. Psychological health, sleep quality, and coping styles to stress facing the COVID-19 in Wuhan, China. Trans/ Psychiatry 2020;10:225.

26 Marelli S, Castelnuovo A, Somma A, et al. Impact of COVID-19 lockdown on sleep quality in university students and administration staff. Journal of Neurology 2020.
27 Gualano MR, Lo Moro G, Voglino G, et al. Effects of Covid-19 Lockdown on mental health and sleep disturbances in Italy. Int $J$ Environ Res Public Health 2020;17:4779.

28 Raja A, Wood F, Joshi HB. The impact of urinary stone disease and their treatment on patients' quality of life: a qualitative study. Urolithiasis 2020;48:227-34.

29 Caraballo C, Khera R, Jones PG, et al. Rates and predictors of patient underreporting of hospitalizations during follow-up after acute myocardial infarction. Circulation: Cardiovascular Quality and Outcomes 2020;13:e006231.

30 Szende A, Janssen B. Cross-Country Analysis of EQ-5D Data. In: Szende A, Janssen B, Cabases J, eds. Self-Reported population health: an international perspective based on EQ-5D. Dordrecht: Springer Netherlands, 2014: 31-6. 